University of Nebraska - Lincoln

DigitalCommons@University of Nebraska - Lincoln

Sociology Department, Faculty Publications

Sociology, Department of

$1-2013$

\title{
The Relationship between Victimization and Substance Use Among Homeless and Runaway Female Adolescents
}

\author{
Kimberly A. Tyler \\ University of Nebraska-Lincoln, kim@ktresearch.net \\ Sarah Gervais \\ University of Nebraska-Lincoln, sgervais2@unl.edu \\ Meghan Davidson \\ University of Nebraska-Lincoln, mdavidson2@unl.edu
}

Follow this and additional works at: https://digitalcommons.unl.edu/sociologyfacpub

Part of the Psychology Commons, and the Sociology Commons

Tyler, Kimberly A.; Gervais, Sarah; and Davidson, Meghan, "The Relationship between Victimization and Substance Use Among Homeless and Runaway Female Adolescents" (2013). Sociology Department, Faculty Publications. 211.

https://digitalcommons.unl.edu/sociologyfacpub/211

This Article is brought to you for free and open access by the Sociology, Department of at DigitalCommons@University of Nebraska - Lincoln. It has been accepted for inclusion in Sociology Department, Faculty Publications by an authorized administrator of DigitalCommons@University of Nebraska - Lincoln. 
Published in Journal of Interpersonal Violence 28:3 (2013), pp. 474-493;

doi: $10.1177 / 0886260512455517$ http://jiv.sagepub.com

Copyright (c) 2013 Kimberly A. Tyler, Sarah J. Gervais, and M. Meghan Davidson.

Published by SAGE Publications on behalf of the American Professional Society on the Abuse of Children. Used by permission.

Published online August 30, 2012.

\title{
The Relationship Between Victimization and Substance Use Among Homeless and Runaway Female Adolescents
}

\author{
Kimberly A. Tyler, Sarah J. Gervais, \\ and M. Meghan Davidson \\ University of Nebraska-Lincoln, Lincoln, NE, USA \\ Corresponding author - Dr. Kimberly A. Tyler, PhD, Department of Sociology, \\ University of Nebraska-Lincoln, 717 Oldfather Hall, Lincoln, NE, 68588-0324, USA; \\ email kim@ktresearch.net
}

\begin{abstract}
Each year, thousands of female adolescents run away from home due to sexual abuse, yet they continue to be victims of sexual assault once on the street. To date, few studies have examined how various forms of victimization are related to different types of substance use. The purpose of this article is to investigate the relationship between street exposure, childhood abuse, and different forms of street victimization with alcohol and marijuana use among 137 homeless and runaway female adolescents. Results from path analysis revealed that child sexual abuse was positively linked to trading sex and sexual and physical victimization. In addition, those who have traded sex experienced greater physical victimization, and who have spent more time away from home, used alcohol more frequently. More-
\end{abstract}


over, trading sex and experiencing more types of sexual victimization were positively linked to more frequent marijuana usage. Age, age at first run, longest time away from home, sexual abuse, and trading sex had significant indirect effects on alcohol and/or marijuana use. Together, these factors accounted for $27 \%$ of the variance in alcohol use and $37 \%$ of the variance in marijuana use.

Keywords: homeless or runaway female adolescents, alcohol, marijuana, abuse, victimization

According to a nationally representative survey on drug use (Johnston, O'Malley, Bachman, \& Schulenberg, 2011a, 2011b), 14\% to 38\% of 13- to 18 -year-old females have drunk alcohol and $5 \%$ to $22 \%$ of this same age group also reported having "been drunk" in the past month. Moreover, this prevalence rate rises for young women: $41 \%$ of college females aged 18 to 25 reported having gotten drunk and 32\% reported binge drinking in the past 30 days. As well, prevalence rates for marijuana are concerning: $7 \%$ to $17 \%$ of 13 - to 18 -year-old females reported marijuana use in the past month and $32 \%$ of college-aged women reported using marijuana in the past year. Although substance use may be somewhat common among general female adolescent populations, the prevalence is much greater among homeless youth.

Research has found that at least three quarters of homeless youth have used alcohol and/or marijuana in their lifetime (Bailey, Camlin, \& Ennett, 1998; Bousman et al., 2005; Greene, Ennett, \& Ringwalt, 1997; Walls \& Bell, 2011) with lifetime substance use rates as high as $97 \%$ (Kral, Molnar, Booth, \& Watters, 1997; Martinez et al., 1998). Though some research has examined risk factors for alcohol and/or illicit drug use (Chen, Tyler, Whitbeck, \& Hoyt, 2004; Kipke, Montgomery, \& MacKenzie, 1993; Kipke, Montgomery, Simon, \& Iverson, 1997; McMorris, Tyler, Whitbeck, \& Hoyt, 2002), there is a paucity of research that examines the link between various forms of victimization and substance use. As such, the purpose of the current article was to examine the relationship between street exposure, childhood abuse, and street victimization with alcohol and marijuana use among 137 homeless and runaway female adolescents. Given that girls experience "sexual abuse at a rate more than 5 times the rate for boys" (Sedlak et al., 2010, pp. 4-3) and that women are generally more likely to experience sexual victimization compared to men (Finkelhor, 1993, 1994; Tyler, Hoyt, Whitbeck, \& Cauce, 2001b), young women were the focus of this study. 


\section{Literature Review}

\section{Substance Use and Homeless Adolescents}

Previous research on homeless youth and runaways has demonstrated a high prevalence of lifetime substance use. In a study of more than 300 runaways aged 11 to 19, Koopman, Rosario, and Rotheram-Borus (1994) found that $67 \%$ of girls have ever used alcohol and $41 \%$ have ever used marijuana. In addition, the authors found that $25 \%$ of girls have used alcohol more than once in the past week and $21 \%$ have used marijuana at least weekly. In a street sample, Greene et al. (1997) found that $79 \%$ of homeless female adolescents had used alcohol and almost $73 \%$ had used marijuana in the past 30 days. Not only do these young women report high prevalence rates, many meet diagnostic criteria for alcohol or drug use dependency (Kipke, Montgomery et al., 1997).

Although few studies employ multivariate models to examine homeless youth and substance use, the findings that do exist show a positive association between length of time respondents are homeless and alcohol use (McMorris et al., 2002) and general substance use (Kipke et al., 1993). Though trading sex, which is exchanging sexual favors for food, shelter, money, and/or drugs, is positively correlated with alcohol and/or drug use (Chen et al., 2004; Kipke et al., 1993; Walls \& Bell, 2011), the findings for early child abuse are less clear; child sexual and physical abuse has been directly tied to substance use albeit only among a nonhomeless sample (Kipke et al., 1993), whereas sexual abuse was found to have an indirect effect on illicit drug use for homeless adolescent females through various other mediators (Chen et al., 2004). Other research, albeit not multivariate in nature, positively links sexual abuse with alcohol and/or marijuana use (Rew, Taylor-Seehafer, \& Fitzgerald, 2001). Although there are no published studies that examined sexual or physical victimization on the street as a risk factor for substance use, general population studies have found a unidirectional relationship between victimization and highrisk behavior (including substance use) among female adolescents (Begle et al., 2011).

Drugs and alcohol serve many purposes for young people having to survive on the streets. For example, some drugs may be used to provide a feeling of warmth during the winter (Ayerst, 1999), as a way to manage the stresses of street life (Kidd, 2003), and as a way to cope with early childhood trauma and other forms of victimization that they routinely experience (Baron, 1997; Kipke, Simon, Montgomery, Unger, \& Iversen, 1997; Stoltz et al., 2007; Tyler \& Cauce, 2002; Tyler, Hoyt, Whitbeck, \& Cauce, 2001a). As such, these findings suggest that drug use may be 
viewed as useful, and even necessary, given the cultural context of street life, which includes having to survive with limited resources.

Child abuse and victimization are also widespread among homeless youth: At least $73 \%$ have experienced physical abuse and one third have suffered sexual abuse prior to leaving home (Stoltz et al., 2007; Tyler \& Cauce, 2002). Trading sex is another form of victimization that numerous homeless youth experience (Greenblatt \& Robertson, 1993; Greene, Ennett, \& Ringwalt, 1999; Halcon \& Lifson, 2004; Tyler \& Johnson, 2006; Van Leeuwen et al., 2004). Finally, research finds that at least one third of these homeless young people have experienced sexual or physical victimization since being on the street (Baron, 1997; Kipke, Simon et al., 1997; Tyler et al., 2001b; Tyler, Melander, \& Noel, 2009).

\section{Substance Use and General Population Studies}

Although there is a dearth of research examining relationships between victimization and substance use for homeless and runaway female adolescents, several published studies have shown relationships between substance use and sexual and/or physical abuse for young women from the general population. Meta-analyses demonstrate a significant link between victimization and substance use for adolescent females but not males (Simpson \& Miller, 2002). Similarly, 40-year-old women who experienced abuse and neglect as children were more likely than controls to report marijuana use during the past year (Widom, Marmorstein, \& Raskin White, 2006). Also, in a nationally representative longitudinal study, victimization (i.e., sexual abuse, physical abuse, and witnessed violence) predicted subsequent high-risk behaviors (i.e., alcohol use, drug use, and delinquent behavior) for female adolescents (Begle et al., 2011). More important, the victimization effects on high-risk behaviors for female adolescents were primarily driven by sexual abuse and not physical abuse or witnessed violence (Begle et al., 2011). Because of the longitudinal nature of this study, researchers demonstrated that sexual abuse was associated with later substance use.

\section{Theoretical Model}

The current article utilizes a risk amplification model (Whitbeck, Hoyt, \& Yoder, 1999) in which early negative experiences (i.e., abuse) set in motion a negative chain of events that are related with more time spent on the street and participation in survival strategies, such as trading sex, which results in increased risk for victimization and, subsequently, greater use of alcohol and marijuana. A fully recursive model 
was hypothesized (i.e., all possible paths are hypothesized with the exception of reciprocal paths) to investigate the cumulative effects of early abuse and street exposure on alcohol and marijuana use among homeless female adolescents.

\section{Hypotheses}

Based on the above literature review, it was hypothesized that those with greater street exposure (i.e., those who run from home at an earlier age, those who have slept on the street at least once in the past week, and those who spend more time away from home) will be more likely to trade sex compared to those with less street exposure (Chen et al., 2004; Tyler et al., 2001a) and will be more likely to experience greater physical and/or sexual victimization (Melander \& Tyler, 2010; Tyler et al., 2001a). Next, it was hypothesized that female adolescents with greater street exposure, as defined above, will be more likely to have higher usage rates of alcohol and marijuana (Kipke et al., 1993; McMorris et al., 2002). In addition, childhood abuse was hypothesized to be positively correlated with trading sex (Chen et al., 2004; Tyler et al., 2001a) and more street victimization (Tyler et al., 2001a; Whitbeck et al., 1999). Because child abuse victims often suffer depression and isolation (e.g., Kendall-Tackett, Williams, \& Finkelhor, 1993; Springer, Sheridan, Kuo, \& Carnes, 2007) and substance use may be a way to cope with these symptoms, it was hypothesized that those who were abused would have greater frequency of alcohol and marijuana use. Because trading sex puts young women in dangerous and vulnerable positions with little or no protection from "clients" (Tyler et al., 2001a), it was hypothesized that trading sex would be positively linked to physical and sexual victimization. Furthermore, because those who trade sex are often desperate (Tyler \& Johnson, 2006), it is possible that they turn to substance use as a way to cope. As such, it was hypothesized that trading sex would be positively associated with alcohol and marijuana use (Chen et al., 2004; Kipke et al., 1993; Walls \& Bell, 2011). Finally, having to cope with the reality of being a victim of physical and/or sexual assault is stressful and is associated with more depressive symptoms among homeless youth (Whitbeck \& Hoyt, 1999). Being intoxicated or "high," however, may alleviate some of the pain. As such, a positive correlation was expected for both sexual and physical victimization with alcohol and marijuana use.

\section{Method}

Data are from the Social Network and Homeless Youth Project, a study designed to examine the effect of social network characteristics on 
homeless youths' HIV risk behaviors. A total of 249 homeless youth (137 females; 112 males) were interviewed in shelters and on the streets from January 2008 to March 2009 in three Midwestern cities. The Institutional Review Board (IRB) at the University of Nebraska-Lincoln approved this study prior to recruitment. The sample includes youth aged 14 to 21 who are considered homeless or a runaway on the night prior to the screening. Homeless refers to youth who have spent the previous night with a stranger, in a shelter or public place, on the street, in a hotel room, staying with friends (e.g., couch surfing), or other places not intended as their resident domicile, whereas runaway refers to those under age 18 who have spent the previous night away from home without the permission of parents or guardians (Ennett, Bailey, \& Federman, 1999).

Interviewers with considerable experience working with homeless and runaway youth conducted the interviews. All interviewers had completed the Collaborative IRB Training Initiative course for the protection of human subjects. Interviewers approached shelter residents and located other eligible respondents in areas of the cities where homeless youth congregate. They varied the times of the day on both weekdays and weekends that they went to these locations over the course of the study. All participants were administered informed consent. Although some respondents were not age of majority, they were mature minors and a request for waiver of parental consent was approved by the supervising IRB. All respondents were told that their responses would remain confidential and that their participation was voluntary. The interviews were conducted in shelter conference rooms or quiet corners of fast-food restaurants if taking the youth back to the shelter was not feasible because of distance or safety concerns. Each interview lasted approximately $45 \mathrm{~min}$ and all participants received US $\$ 25$ for their involvement and US $\$ 5$ for a meal. Referrals for shelter, counseling services, and food services were also offered to youth. The response rate was $97 \%$ based on the number of initial contacts.

\section{Measures}

Because homeless youth are such a vulnerable group with many engaging in high-risk behaviors (e.g., trading sex, delinquent activities) and experiencing negative outcomes (e.g., sexual victimization), they have unique circumstances that often cannot be adequately assessed with traditional, standardized scales. Thus, where possible, we present internal consistency reliabilities and construct validity found in other studies of homeless youth using the same or similar measures as those used in the current study. 
Dependent variables. Alcohol use was measured by asking respondents how often they have drank beer, wine, or liquor in the past 6 months $(0=$ never, $1=$ a few times, $2=$ monthly, $3=$ weekly, $4=$ daily $)$. The three items were summed; a higher score indicated greater frequency of alcohol consumption $(\alpha=.72)$. These items are consistent with prior alcohol use studies among homeless and general adolescent populations (Barnes, Welte, \& Hoffman, 2002; McMorris et al., 2002). Similar to other studies (Greene et al., 1997), 69\% of participants reported alcohol use.

Marijuana use was a single item that asked respondents how often they smoked marijuana in the past 6 months $(0=$ never, $1=a$ few times, 2 $=$ monthly, $3=$ weekly, $4=$ daily $)$. The current $45 \%$ prevalence rate is higher than the 35\% rate found among female shelter youth (Green et al., 1997).

Independent variables. Respondent age ranged from 14 to 21 . Age at first run was an open-ended question that asked, "How old were you when you first ran away or left home?" Ever slept on the street was measured by asking, "On average, how many nights a week do you spend on the street?" Because this variable was skewed, it was dichotomized into $0=$ never sleep on the street and $1=$ sleep on the street, on average, at least once a week. Longest time away from home was an open-ended question that asked, "What was the longest time period that you spent away from home?" Response categories were collapsed into $1=1$ month or less, $2=2$ to 4 months, $3=5$ to 9 months, $4=10$ to 19 months, and $5=20$ or more months. These street exposure items are important correlates of various outcomes among homeless youth and have been conceptualized similarly to what is reported in the current study (see Berdahl, Hoyt, \& Whitbeck, 2005; Chapple, Johnson, \& Whitbeck, 2004; Chen, Thrane, Whitbeck, Johnson, \& Hoyt, 2007; Kipke, Montgomery et al., 1997).

Child abuse included two questions: "Were you ever physically abused as a child (under age 18)?" and "Were you ever sexually abused as a child (under age 18)?" $(0=$ no, $1=$ yes).

Traded sex was measured by asking participants whether they have ever traded sex for food, shelter, money, or drugs $(0=n o, 1=y e s)$. In addition, an open-ended question asked youth what kinds of things they had done to survive on the streets when they had few other options. Those who indicated that they had traded sex were also included in this count.

Sexual victimization included four items such as whether respondent had been forced to do something sexual or had been sexually assaulted and/or raped since leaving home $(0=$ never to $3=$ many times -5 or more). Due to skewness, the four individual items were first dichotomized and then summed; a higher score indicated more types of sexual 
victimization $(\alpha=.84)$. Using similar items, Melander and Tyler (2010) found the same reliability $(\alpha=.84)$ among homeless young adult males and females.

Physical victimization included five items such as the frequency with which they were beaten up or robbed since leaving home $(0=$ never to $3=$ many times -5 or more). The items were summed; a higher score indicated greater physical victimization $(\alpha=.70)$. These same items have been used with other homeless populations (Whitbeck \& Simons, 1990; $a=.82$ ).

\section{Results}

\section{Sample Characteristics}

Of the original sample of 249 adolescents, 137 or $55 \%$ were female and were selected for the current analyses. Almost half $(47.4 \%)$ of the young women identified as White, 21.2\% Black, 10.9\% Hispanic, 8.0\% American Indian or Alaskan Native, 1.5\% Asian, and 11.0\% biracial or multiracial. The mean age at first run was 13.8 years, and $21 \%$ had spent, on average, at least one night per week on the street. The average for the longest time away from home was between 2 and 9 months. Just more than one half $(51 \%)$ had been physically abused at least once and $43 \%$ reported being a victim of sexual abuse on at least one occasion. Just more than $20 \%$ had traded sex at least one time and on average, the young women had experienced approximately two different forms of sexual victimization since being on the street. Finally, young women reported approximately "monthly" average alcohol use and indicated using marijuana "a few times" on average.

\section{Bivariate Correlations}

Pearson correlation coefficients for all measures are presented in Table 1 with the means, standard deviations $(S D)$, and range. Sleeping on the street was significantly correlated with trading sex $(r=.31, p<.01)$, sexual and physical victimization $(r=.24$ and $r=.31, p<.01$, respectively), and more alcohol $(r=.27, p<.01)$ and marijuana use $(r=.21, p<$ $.05)$. Sexual victimization was positively correlated with alcohol and marijuana use ( $r=.31$ and $r=.26, p<.01$, respectively) as was physical victimization ( $r=.40$ and $r=.22, p<.01$, respectively).

\section{Procedure}

A fully recursive path model was estimated using the maximum likelihood (ML) procedure in Mplus 6.0 (Muthen \& Muthen, 1998-2007). The 
Table 1. Correlation Matrix for Alcohol and Marijuana Use

\begin{tabular}{|c|c|c|c|c|c|c|c|c|c|c|c|}
\hline & 1 & 2 & 3 & 4 & 5 & 6 & 7 & 8 & 9 & 10 & 11 \\
\hline 1. Age & - & & & & & & & & & & \\
\hline 2. Age at first run & .11 & - & & & & & & & & & \\
\hline $\begin{array}{l}\text { 3. Ever slept } \\
\text { on street }\end{array}$ & $.27^{* *}$ & $*-.05$ & - & & & & & & & & \\
\hline $\begin{array}{l}\text { 4. Longest time } \\
\text { away }\end{array}$ & .12 & -.02 & $.19^{*}$ & - & & & & & & & \\
\hline 5. Sexual abuse & .14 & $-.34^{* *}$ & .09 & -.01 & - & & & & & & \\
\hline 6. Physical abuse & .11 & $-.34^{* *}$ & .04 & -.04 & $.55^{* *}$ & - & & & & & \\
\hline 7. Traded sex & $.25^{* *}$ & * $-.19^{*}$ & $.31^{* *}$ & $.18^{*}$ & $.33^{* *}$ & $.20^{*}$ & - & & & & \\
\hline $\begin{array}{l}\text { 8. Sexual } \\
\text { victimization }\end{array}$ & $.20^{*}$ & $-.20^{*}$ & $.24^{* *}$ & .03 & $.53^{* *}$ & $.37^{* *}$ & $.53^{* *}$ & - & & & \\
\hline $\begin{array}{l}\text { 9. Physical } \\
\text { victimization }\end{array}$ & $.24^{* *}$ & $*-.12$ & $.31^{* *}$ & $.23^{* *}$ & $.38^{* *}$ & $.25^{* *}$ & $.46^{* *}$ & $.55^{* *}$ & - & & \\
\hline 10. Alcohol use & .17 & -.07 & $.27^{* *}$ & .01 & $.20^{*}$ & .16 & $.25^{* *}$ & $.31^{* *}$ & $.40^{* *}$ & - & \\
\hline 11. Marijuana use & .06 & -.15 & $.21^{*}$ & .01 & $.20^{*}$ & .09 & $.33^{* *}$ & $.26^{* *}$ & $.22^{* *}$ & $.62^{* *}$ & - \\
\hline Mean & 18.35 & 13.83 & .21 & 2.45 & .43 & .51 & .21 & 1.79 & 3.51 & 1.94 & .96 \\
\hline$S D$ & 1.85 & 3.12 & .41 & 1.49 & .50 & .50 & .41 & 1.60 & 2.89 & 2.22 & 1.33 \\
\hline Range & $4-21$ & $2-20$ & $0-1$ & $1-5$ & $0-1$ & $0-1$ & $0-1$ & $0-4$ & $0-15$ & $0-9$ & $0-4$ \\
\hline
\end{tabular}

$N=137$

${ }^{*} p<.05 ;{ }^{* *} p<.01$

statistical assumptions of ML estimation (e.g., multivariate normality of the endogenous variables) were satisfied. This modeling takes into account both the direct effects as well as the indirect effects through trading sex and sexual and physical victimization. Although some prior research on homeless youth has combined alcohol and/or different types of drugs (Chen et al., 2004; Koopman et al., 1994), other studies have examined them separately (Green et al., 1997; McMorris et al., 2002). Because access to these drugs may vary, as well as the reasons for their usage, and alcohol consumption is legal (for those aged 21 and above) and marijuana use is not, we investigated these two drugs separately.

\section{Direct Effects}

Alcohol model. Standardized path coefficients for the significant correlates of alcohol use are shown in Figure 1. Results revealed that female adolescents who were older $(\beta=.17)$, who had run away from home at an earlier age $(\beta=-.27)$, and who were victims of sexual abuse $(\beta=.22)$ were more likely to have traded sex. In addition, the greater amount of time away from home, the more likely these young women were to expe- 


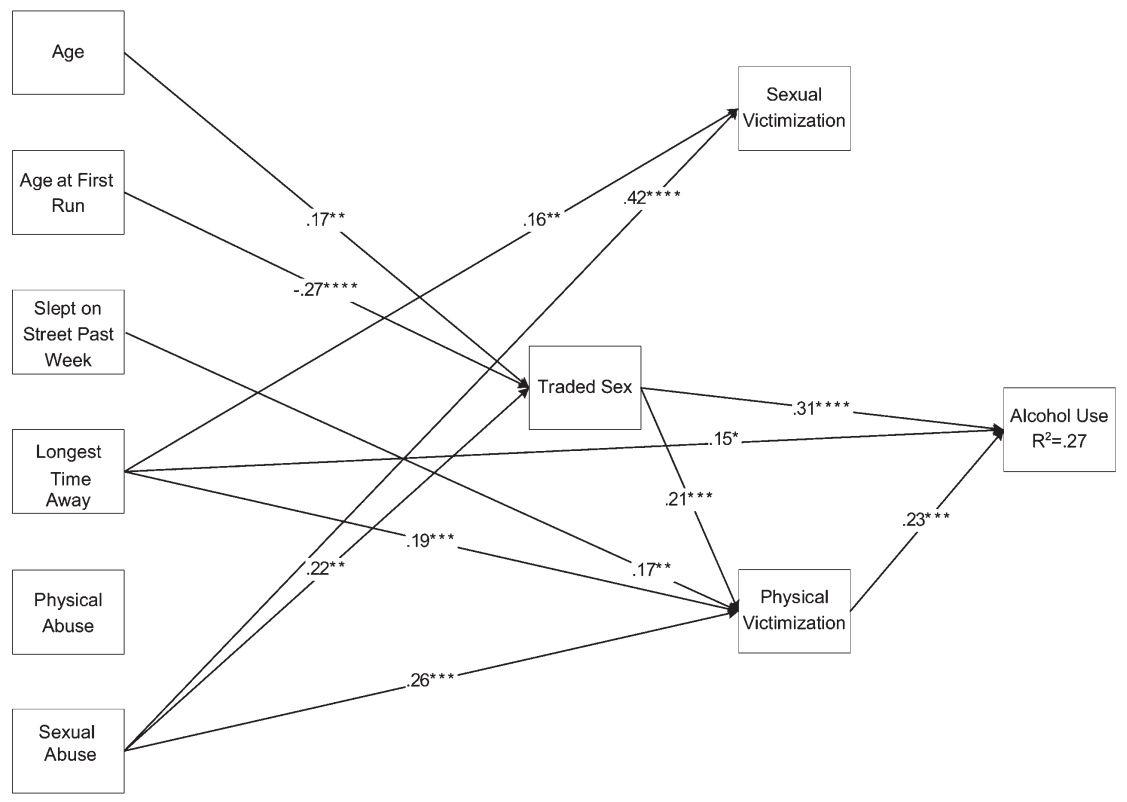

Figure 1. Standardized path coefficients for correlates of alcohol use.

${ }^{*} p \leq .10 ;{ }^{* *} p \leq .05 ;{ }^{* * *} p \leq .01 ;{ }^{* * *} p<.001$

rience more types of sexual victimization $(\beta=.16)$. Being a victim of sexual abuse was positively associated with street sexual victimization $(\beta=$ .42 ). Those who experienced more physical victimization were found to have spent at least one night on the street $(\beta=.17)$, to have been away from home longer $(\beta=.19)$, to have experienced sexual abuse $(\beta=.26)$, and to have traded sex $(\beta=.21)$. Finally, female adolescents who were more likely to have greater alcohol consumption were found to have spent a longer period of time away from home $(\beta=.15)$, to have experienced more physical victimization $(\beta=.23)$, and to have traded sex $(\beta=$ .31). These variables explained $27 \%$ of the variance in alcohol use.

Marijuana model. Standardized path coefficients for the significant correlates of marijuana use are shown in Figure 2. Results revealed that girls who were older $(\beta=.17)$, who had run away from home at an earlier age $(\beta=-.27)$, and who had experienced sexual abuse $(\beta=$ .22) were significantly more likely to have traded sex. In addition, the longer youth were away from home the more likely they were to experience more types of sexual victimization $(\beta=.16)$. Being a victim of sexual abuse was also positively associated with more types of sexual 


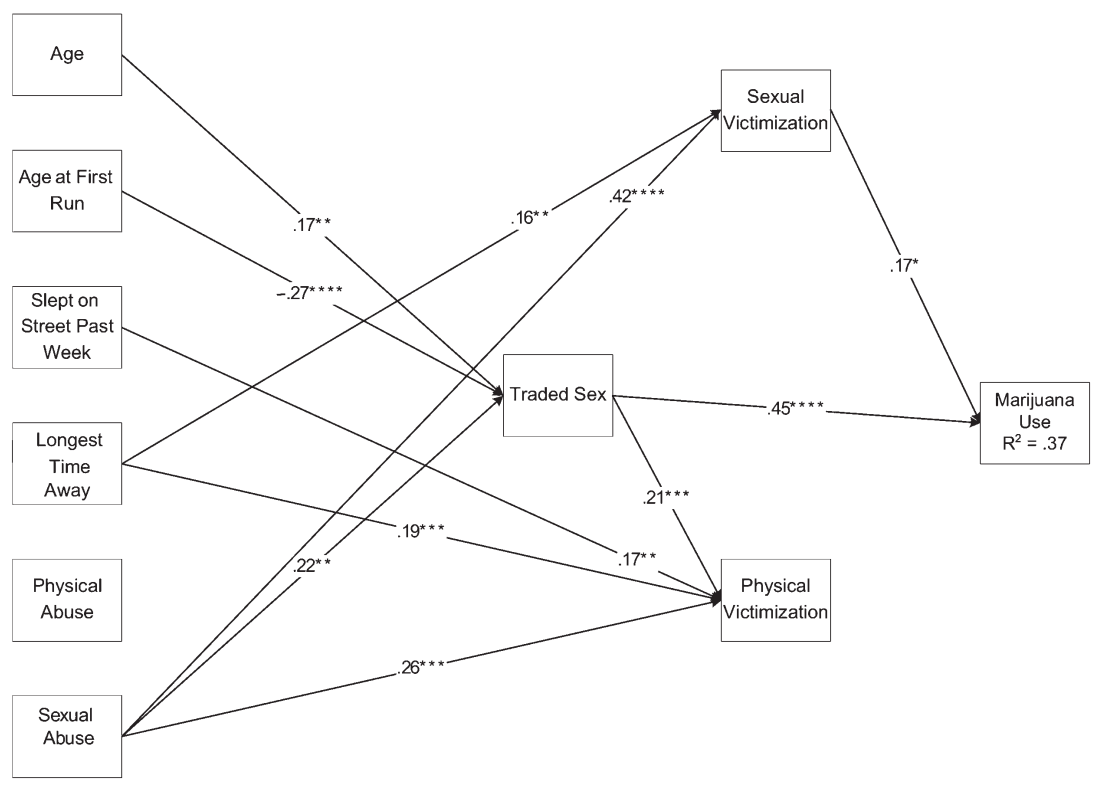

Figure 2. Standardized path coefficients for correlates of marijuana use.

${ }^{*} p \leq .10 ;{ }^{* *} p \leq .05 ;{ }^{* * *} p \leq .01 ; * * * *<.001$

victimization on the street $(\beta=.42)$. Girls who experienced more physical victimization since leaving home were significantly more likely to have spent at least one night on the street $(\beta=.17)$, to have been away from home for a longer time period $(\beta=.19)$, to have experienced sexual abuse $(\beta=.26)$, and to have traded sex $(\beta=.21)$. Finally, female adolescents who experienced greater sexual victimization $(\beta=.17)$ and those who traded sex $(\beta=.45)$ were significantly more likely to have used marijuana more frequently in the past 6 months compared to their counterparts. These variables accounted for $37 \%$ of the variance in marijuana use.

\section{Indirect Effects}

The direct, indirect, and total effects for the full model on alcohol use are shown in Table 2 (top portion). The results revealed that although only three variables had direct effects on alcohol use (i.e., traded sex, lon- 
Table 2. Full Model Results (Standardized)

\begin{tabular}{|c|c|c|c|c|c|c|}
\hline \multirow[b]{2}{*}{ Variables } & \multicolumn{2}{|c|}{ Direct Effect } & \multicolumn{2}{|c|}{$\begin{array}{c}\text { Total } \\
\text { Indirect Effect }\end{array}$} & \multicolumn{2}{|c|}{ Total Effect } \\
\hline & Estimate & $S E$ & Estimate & $S E$ & Estimate & $S E$ \\
\hline \multicolumn{7}{|l|}{ Alcohol use } \\
\hline Age & -.005 & .080 & $.087^{* *}$ & .039 & .081 & .086 \\
\hline Age at first run & .082 & .084 & $-.085^{* *}$ & .043 & -.003 & .089 \\
\hline Ever slept on street & -.091 & .077 & .049 & .038 & -.042 & .082 \\
\hline Longest time away & $.152^{*}$ & .079 & $.095^{* *}$ & .040 & $.247^{* * *}$ & .083 \\
\hline Sexual abuse & -.039 & .100 & $.174^{* * *}$ & .058 & .135 & .099 \\
\hline Physical abuse & .072 & .091 & -.006 & .044 & .066 & .099 \\
\hline Traded sex & $.310^{* * * *}$ & .080 & $.057^{* *}$ & .026 & $.367^{* * * *}$ & .079 \\
\hline Sexual victimization & .083 & .098 & & & & \\
\hline Physical victimization & $.233^{* * *}$ & .094 & & & & \\
\hline \multicolumn{7}{|l|}{ Marijuana use } \\
\hline Age & .086 & .074 & $.106^{* *}$ & .045 & $.192^{* *}$ & .084 \\
\hline Age at first run & .051 & .078 & $-.125^{* * *}$ & .049 & -.073 & .087 \\
\hline Ever slept on street & -.018 & .071 & .035 & .045 & .017 & .081 \\
\hline Longest time away & -.069 & .074 & $.102^{* *}$ & .047 & $.171^{* *}$ & .083 \\
\hline Sexual abuse & -.020 & .093 & $.211^{* * *}$ & .063 & $.191^{* *}$ & .097 \\
\hline Physical abuse & -.013 & .085 & -.018 & .052 & -.032 & .098 \\
\hline Traded sex & $.447^{* * * *}$ & .071 & $.044^{*}$ & .024 & $.491^{* * * *}$ & .070 \\
\hline Sexual victimization & $.167^{*}$ & .091 & & & & \\
\hline Physical victimization & .134 & .089 & & & & \\
\hline
\end{tabular}

${ }^{*} p \leq .10 ;{ }^{* *} p \leq .05 ;{ }^{* * *} p \leq .01 ;{ }^{* * * *} p<.001$

gest time away, and physical victimization) several variables had indirect effects. Specifically, older youth, those who ran from home at an earlier age, and those who experienced sexual abuse were more likely to have traded sex, which in turn was positively associated with alcohol use. In addition, female adolescents who spent a longer time away from home, who were sexually abused, and who have traded sex experienced higher rates of physical victimization, which in turn was positively correlated with alcohol use. The bottom portion of Table 2 shows that trading sex and sexual victimization have a direct effect on marijuana use. In addition age, age at first run, and sexual abuse all had indirect effects on marijuana through trading sex. Finally, longest time away and sexual abuse both had an indirect effect on marijuana use through sexual victimization. 


\section{Discussion}

The current study examined the associations between street exposure, childhood abuse, and street victimization with alcohol and marijuana use among 137 homeless and runaway female adolescents. Although previous research has investigated risk factors for substance use (Chen et al., 2004; Kipke et al., 1993; Kipke, Montgomery et al., 1997; McMorris et al., 2002), very few studies have examined its link with various forms of victimization. Furthermore, few studies have used multivariate models to examine relationships between victimization and substance use; thus, the unique contributions of different types of victimization are unclear. The results from the current study show that greater street exposure and child sexual abuse both had significant indirect effects on alcohol and marijuana usage through trading sex as well as through sexual and/or physical victimization. Trading sex was a risk factor for both alcohol and marijuana use, whereas physical victimization was correlated with alcohol use and sexual victimization was correlated with marijuana use. Being a victim of early sexual abuse continues to have a negative impact on homeless and runaway female adolescents long after they leave home. In addition, once on the streets, they continue to experience other forms of victimization, which are also positively linked to greater frequency of alcohol and marijuana use.

Consistent with prior research (Greene et al., 1997; Koopman et al., 1994), respondents in the current study reported high rates of alcohol and marijuana usage. Substance use among homeless youth has been found to serve many purposes, including staying awake for longer time periods, keeping warm during winter months (Ayerst, 1999), and managing the stresses associated with surviving on the street (Kidd, 2003). It is also possible that these young women are using substances as a way to cope with numerous negative experiences, including child sexual abuse, having to trade sex for specific items of necessity, and being sexually and/ or physically victimized on the street. Support for this coping model has been found among normative populations (Begle et al., 2011; Lo, Kim, \& Church, 2008).

As hypothesized, sexual abuse was positively associated with trading sex and sexual and physical victimization (Chen et al., 2004; Tyler et al., 2001a; Whitbeck et al., 1999). Also consistent with hypotheses, trading sex was positively correlated with both alcohol and marijuana use (Chen et al., 2004; Kipke et al., 1993; Walls \& Bell, 2011). Furthermore, sexual victimization was positively related to marijuana use whereas physical victimization was positively linked to alcohol use. These differences in substances used for the two types of street victimization are interesting to note. Perhaps homeless and runaway female adolescents cope with the 
less intimate victimization (i.e., physical assault) through alcohol use and manage the more violating and intimate sexual victimization via marijuana use. Sexual abuse also had an indirect effect on alcohol and marijuana use through trading sex (Chen et al., 2004). Victims of sexual abuse tend to have lower self-esteem and are likely to suffer depression and isolation (Kendall-Tackett et al., 1993; Springer et al., 2007). As a result, they may be more likely to become involved in unhealthy relationships where they are revictimized and exploited such as being forced to trade sex by their partners (Tyler \& Johnson, 2006). In addition, experiencing sexual abuse may result in young women learning the social scripts necessary for becoming victims of violence as they have internalized rationalizations for interpersonal violence. Because of the trauma associated with these various forms of abuse and victimization, some young women may turn to substance use as a way to cope.

Consistent with a risk amplification model (Whitbeck et al., 1999), greater street exposure (i.e., age at first run and longest time away from home) is a risk factor for substance use as hypothesized. That is, being away from home for longer time periods is positively related to sexual and physical victimization and alcohol use (Kipke et al., 1993; McMorris et al., 2002). Furthermore, being away from home for longer periods of time indirectly leads to greater frequency of alcohol and marijuana use through physical victimization and sexual victimization, respectively. In addition, running away from home at an earlier age is indirectly associated with greater frequency of alcohol and marijuana use through trading sex. Greater exposure to the street likely increases young women's chances of coming into contact with individuals who may exploit them, which increases their likelihood of victimization (Hoyt, Ryan, \& Cauce, 1999; Tyler et al., 2001a). In addition, because street exposure is linked to involvement with other street youth, this is likely to amplify young women's chances of engaging in deviant behaviors, including substance use (Whitbeck \& Hoyt, 1999). Finally, because young women are often coerced into trading sex by their partners (Tyler \& Johnson, 2006) or trade sex as a means of survival (e.g., finding shelter for the night), they may use alcohol and marijuana as a way to dull the pain of having engaged in this behavior.

Although both the bivariate and multivariate analyses showed significant relationships between sexual abuse and alcohol and marijuana use, physical abuse was not associated with any of the outcome variables in either analyses, contrary to expectations. It is possible that physical abuse is not as salient as sexual abuse given that we focused on young women who experience higher rates of sexual abuse compared to young men (Sedlak et al., 2010; Tyler \& Cauce, 2002; Tyler et al., 2001b). Though surprising, this finding is consistent with recent research showing that sex- 
ual and not physical abuse predicts substance use among female adolescents in the general population (Begle et al., 2011). It is possible that experiencing sexual abuse is particularly traumatic for females compared to other forms of abuse (e.g., physical, psychological) and, as a result, is related to more adverse outcomes, including substance use.

\section{Limitations}

Some limitations need to be noted. First, the generalizability of results are limited due to the reliance on a convenience sample as it is not possible to randomly sample homeless populations (Wright, Allen, \& Devine, 1995). Second, the use of cross-sectional data does not allow for causal arguments. Previous studies of general adolescent populations, however, find that victimization leads to substance use (Begle et al., 2011) rather than vice versa. In addition, because youth were asked to reflect on experiences that occurred during specific time periods (e.g., before leaving home for child abuse) this aids with temporal ordering of variables. Third, the use of face-to-face interviews may have led to underreporting of abuse due to social desirability. As well, underreporting of abuse may have occurred because homeless youth often do not consider certain acts to be abusive (Tyler \& Melander, 2009); this is particularly salient given the use of single-item indicators for physical and sexual abuse in the current study.

\section{Conclusion}

Overall, these results highlight that many young women who experience childhood sexual abuse are at greater risk for repeating the cycle of violence, both on the street and potentially in future relationships. The current study adds to the limited literature in this area by simultaneously investigating street exposure, child abuse, and different forms of street victimization with alcohol and marijuana use rather than examining these constructs individually. More important, these variables accounted for $27 \%$ and $37 \%$ of the variance in alcohol use and in marijuana use, respectively, among homeless and runaway female adolescents. Future research may wish to replicate these findings to examine whether similar relationships exist between various forms of victimization and substance use among homeless youth and young adults.

Acknowledgments - This article is based on research supported by a grant from the National Institute on Drug Abuse (DA021079). Dr. Kimberly A. Tyler, PI. 


\section{References}

Ayerst, S. L. (1999). Depression and stress in street youth. Adolescence, 34(135), 567-575.

Bailey, S. L., Camlin, C. S., \& Ennett, S. T. (1998). Substance use and risky sexual behavior among homeless and runaway youth. Journal of Adolescent Health, 23(6), 378-388.

Barnes, G. M., Welte, J. W., \& Hoffman, J. H. (2002). Relationship of alcohol use to delinquency and illicit drug use in adolescents: Gender, age, and racial/ethnic differences. Journal of Drug Issues, 32, 153-178. Baron, S. W. (1997). Risky lifestyles and the link between offending and victimization. Studies on Crime and Crime Prevention, 6, 53-71.

Begle, A. M., Hanson, R. F., Danielson, C., McCart, M. R., Ruggiero, K. J., Amstadter, A. B., . . Kilpatrick, D. G. (2011). Longitudinal pathways of victimization, substance use, and delinquency: Findings from the National Survey of Adolescents. Addictive Behaviors, 36, 682-689. doi:10.1016/j. addbeh.2010.12.026

Berdahl, T. A., Hoyt, D. R., \& Whitbeck, L. B. (2005). Predictors of first mental health service utilization among homeless and runaway adolescents. Journal of Adolescent Health, 37, 145-154.

Bousman, C. A., Blumberg, E. J., Shillington, A. M., Hovell, M. F., Ji, M., Lehman, S., \& Clapp, J. (2005). Predictors of substance use among homeless youth in San Diego. Addictive Behaviors, 30, 1100-1110.

Chapple, C. L., Johnson, K. D., \& Whitbeck, L. B. (2004). Gender and arrest among homeless and runaway youth: An analysis of background, family, and situational factors. Youth Violence and Juvenile Justice, 2, 129-147.

Chen, X., Thrane, L., Whitbeck, L. B., Johnson, K. D., \& Hoyt, D. R. (2007). Onset of conduct disorder, use of delinquent subsistence strategies, and street victimization among homeless and runway adolescents in the Midwest. Journal of Interpersonal Violence, 22, 1156-1183.

Chen, X., Tyler, K. A., Whitbeck, L. B., \& Hoyt, D. R. (2004). Early sexual abuse, street adversity, and drug use among female homeless and runaway adolescents in the Midwest. Journal of Drug Issues, 34, 1-21.

Ennett, S. T., Bailey, S. L., \& Federman, E. B. (1999). Social network characteristics associated with risky behaviors among runaway and homeless youth. Journal of Health and Social Behavior, 40, 63-78.

Finkelhor. D. (1993). Epidemiological factors in the clinical identification of child sexual abuse. Child Abuse \& Neglect, 17, 67-70.

Finkelhor, D. (1994). Current information on the scope and nature of child sexual abuse. The Future of Children, 4, 31-53. 
Greenblatt, M., \& Robertson, M. J. (1993). Life-styles, adaptive strategies, and sexual behaviors of homeless adolescents. Hospital and Community Psychiatry, 44, 1177-1180.

Greene, J. M., Ennett, S. T., \& Ringwalt, C. L. (1997). Substance use among runaway and home-less youth in three national samples. American Journal of Public Health, 87, 229-235.

Greene, J. M., Ennett, S. T., \& Ringwalt, C. L. (1999). Prevalence and correlates of survival sex among runaway and homeless youth. American Journal of Public Health, 89, 1406-1409.

Halcon, L. L., \& Lifson, A. R. (2004). Prevalence and predictors of sexual risks among homeless youth. Journal of Youth and Adolescence, 33, 71-80.

Hoyt, D. R., Ryan, K. D., \& Cauce, A. M. (1999). Personal victimization in a high-risk environment: Homeless and runaway adolescents. Journal of Research in Crime and Delinquency, 36, 371-391.

Johnston, L. D., O’Malley, P. M., Bachman, J. G., \& Schulenberg, J. E. (2011a). Monitoring the Future national survey results on drug use, 1975-2010. Vol. 1: Secondary school students. Ann Arbor: Institute for Social Research, the University of Michigan.

Johnston, L. D., O'Malley, P. M., Bachman, J. G., \& Schulenberg, J. E. (2011b). Monitoring the Future national survey results on drug use, 1975-2010. Vol. 2: College students and adults ages 19-50. Ann Arbor: Institute for Social Research, the University of Michigan.

Kendall-Tackett, K. A., Williams, L. M., \& Finkelhor, D. (1993). Impact of sexual abuse on children: A review and synthesis of recent empirical studies. Psychological Bulletin, 113, 164-180.

Kidd, S. A. (2003). Street youth: Coping and interventions. Child and Adolescent Social Work Journal, 20, 235-261.

Kipke, M. D., Montgomery, S. B., \& MacKenzie, R. G. (1993). Substance use among youth seen at a community-based health clinic. Journal of Adolescent Health, 14, 289-294.

Kipke, M. D., Montgomery, S. B., Simon, T. R., \& Iverson, E. F. (1997). Substance abuse disorders among runaway and homeless youth. Substance Use $\mathcal{E}$ Misuse, 32, 969-986.

Kipke, M. D., Simon, T. R., Montgomery, S. B., Unger, J. B., \& Iversen, E. F. (1997). Homeless youth and their exposure to and involvement in violence while living on the streets. Journal of Adolescent Health, 20, 360-367.

Koopman, C., Rosario, M., \& Rotheram-Borus, M. J. (1994). Alcohol and drug use and sexual behaviors placing runaways at risk for HIV infection. Addictive Behaviors, 19, 95-103. 
Kral, A. H., Molnar, B. E., Booth, R. E., \& Watters, J. K. (1997). Prevalence of sexual risk behavior and substance use among runaway and homeless adolescents in San Francisco, Denver and New York City. International Journal of STD and AIDS, 8, 109-117.

Lo, C. C., Kim, Y. S., \& Church, W. T., II. (2008). The effects of victimization on drug use: A multilevel analysis. Substance Use $\mathcal{E}$ Misuse, 43, 1340-1361.

Martinez, T. E., Gleghorn, A., Marx, R., Clements, K., Boman, M., \& Katz, M. H. (1998). Psychosocial histories, social environment, and HIV risk behaviors of injection and noninjection drug using homeless youths. Journal of Psychoactive Drugs, 30, 1-10.

McMorris, B. J., Tyler, K. A., Whitbeck, L. B., \& Hoyt, D. R. (2002). Familial and "on-the-street" risk factors associated with alcohol use among homeless and runaway adolescents. Journal of Studies on Alcohol, 63, 34-43.

Melander, L. A., \& Tyler, K. A. (2010). The effect of early maltreatment, victimization, and partner violence on HIV risk among homeless young adults. Journal of Adolescent Health, 47, 575-581.

Muthen, L. K., \& Muthen, B. O. (1998-2007). Mplus user's guide (5th ed.). Los Angeles, CA.

Rew, L., Taylor-Seehafer, M., \& Fitzgerald, M. L. (2001). Sexual abuse, alcohol and other drug use, and suicidal behaviors in homeless adolescents. Issues in Comprehensive Pediatric Nursing, 24, 225-240.

Sedlak, A. J., Mettenburg, J., Basena, M., Petta, I., McPherson, K., Greene, A., \& Li, S. (2010). Fourth National Incidence Study of Child Abuse and Neglect (NIS- 4): Report to Congress. Washington, DC: U.S. Department of Health and Human Services, Administration for Children and Families.

Simpson, T. L., \& Miller, W. R. (2002). Concomitance between childhood sexual and physical abuse and substance use problems: A review. Clinical Psychology Review, 22, 27-77.

Springer, K. W., Sheridan, J., Kuo, D., \& Carnes, M. (2007). Long-term physical and mental health consequences of childhood physical abuse: Results from a large population-based sample of men and women. Child Abuse $\mathcal{E}$ Neglect, 31, 517-530.

Stoltz, J. M., Shannon, K., Kerr, T., Zhang, R., Montaner, J. S., \& Wood, E. (2007). Associations between childhood maltreatment and sex work in a cohort of drugusing youth. Social Science \& Medicine, 65, 1214-1221.

Tyler, K. A., \& Cauce, A. M. (2002). Perpetrators of early physical and sexual abuse among homeless and runaway adolescents. Child Abuse E Neglect, $26,1261-1274$. 
Tyler, K. A., Hoyt, D. R., Whitbeck, L. B., \& Cauce, A. M. (2001a). The impact of childhood sexual abuse on later sexual victimization among runaway youth. Journal of Research on Adolescence, 11, 151-176.

Tyler, K. A., Hoyt, D. R., Whitbeck, L. B., \& Cauce, A. M. (2001b). The effects of a high-risk environment on the sexual victimization of homeless and runaway youth. Violence \& Victims, 16, 441-455.

Tyler, K. A., \& Johnson, K. A. (2006). Trading sex: Voluntary or coerced? The experiences of homeless youth. Journal of Sex Research, 43, 208-216.

Tyler, K. A., \& Melander, L. A. (2009). Discrepancies in reporting of physical and sexual abuse among homeless youth. Journal of Child Sexual Abuse, 18, 513-531.

Tyler, K. A., Melander, L. A., \& Noel, H. (2009). Bidirectional partner violence among homeless young adults: Risk factors and outcomes. Journal of Interpersonal Violence, 24, 1014-1035.

Van Leeuwen, J. M., Hopfer, C., Hooks, S., White, R., Petersen, J., \& Pirkopf, J. (2004). A snapshot of substance abuse among homeless and runaway youth in Denver, Colorado. Journal of Community Health, 29, 217-229.

Walls, N. E., \& Bell, S. (2011). Correlates of engaging in survival sex among homeless youth and young adults. Journal of Sex Research, 48, 423-436.

Whitbeck, L. B., \& Hoyt, D. R. (1999). Nowhere to grow: Homeless and runaway adolescents and their families. New York, NY: Aldine de Gruyter.

Whitbeck, L. B., Hoyt, D. R., \& Yoder, K. A. (1999). A risk-amplification model of victimization and depressive symptoms among runaway and homeless adolescents. American Journal of Community Psychology, 27, 273-296.

Whitbeck, L. B., \& Simons, R. L. (1990). Life on the streets: The victimization of runaway and homeless adolescents. Youth \& Society, 22, 108-125.

Widom, C. S., Marmorstein, N. R., \& Raskin White, H. (2006). Childhood victimization and illicit drug use in middle adulthood. Psychology of Addictive Behaviors, 20, 394-403.

Wright, J. D., Allen, T. L., \& Devine, J. A. (1995). Tracking non-traditional populations in longitudinal studies. Evaluation \& Program Planning, 18, 267-277. 


\section{The Authors}

Kimberly A. Tyler, PhD, is a professor in the Department of Sociology at the University of Nebraska-Lincoln. Her research interests include homelessness, child abuse and neglect, partner violence, substance use, and other high-risk behaviors among adolescents and youth.

Sarah J. Gervais, PhD, is an assistant professor of psychology in the Law and Social Psychology programs at the University of Nebraska-Lincoln. Her research focuses on power and discrimination. Examining behaviors like the objectifying gaze, patronization, and interpersonal confrontation, she has found that the discriminatory acts of powerful people are often more subtle and nuanced than previously thought, but they still have negative legal and social consequences for recipients. She has a dual PhD in psychology and women's studies from the Pennsylvania State University.

M. Meghan Davidson, $\mathrm{PhD}$, is a counseling psychologist and assistant professor at the University of Nebraska-Lincoln. Her research interests include intimate partner violence, sexual assault, prevention and early intervention, and measurement. She received her doctoral degree from the University of Missouri-Columbia and completed her predoctoral internship at the University of Oregon Counseling and Testing Center. She is a licensed psychologist. 